\title{
Transformation or Socio-Cultural Identity: Style Shifting on Language Used in Tanzanian Film Industry (Bongo Movies)
}

\author{
Rafiki Yohana Sebonde \\ Department of Foreign Languages and Literature, The University of Dodoma, Dodoma, Tanzania \\ Email address: \\ ryohana@yahoo.co.uk \\ To cite this article: \\ Rafiki Yohana Sebonde. Transformation or Socio-Cultural Identity: Style Shifting on Language Used in Tanzanian Film Industry (Bongo \\ Movies). International Journal of Language and Linguistics. Vol. 6, No. 1, 2018, pp. 8-14. doi: 10.11648/j.ij11.20180601.12
}

Received: January 8, 2018; Accepted: January 25, 2018; Published: February 26, 2018

\begin{abstract}
This paper seeks to demonstrate how there has been a manifestation of a style-shifting on the languages used in Tanzanian film industry (Bongo movies), from less to highly prestigious language; Kiswahili and English being the case. That, when people are highly negotiating for the use of Kiswahili in different domains, in Tanzanian film industry there is a style shifting from Kiswahili to English. This paper investigates whether code-switching and use of English titles and subtitles in the Bongo Movies is a product of language transformation or a way of constructing a new socio-cultural identity through relating to English usage, the language of authority and economic power, or is for attracting more audience or outside country market or whether it is the outcome of free economy, market and privatization or internationalization and globalization where English seems to be inevitable. The study was guided by Speech Accommodation Theory to clarify motivations for adjustment in speech patterns. Data for this study were collected through watching and reviewing 11 DVDs of Bongo movies produced after year 2000 to trace the status of language transformation, and interviewing 10 film stakeholders to examine the possible factors for style shifting on language used in Tanzania films. The data revealed that the use of English titles and subtitles, and codeswitching from Kiswahili to English are the linguistic strategies for constructing socio-cultural identity, the manifestation of a multilingual Tanzania, film contextualization, free market economy particularly the need to attract and accommodate the international audience, co-production with outside companies, sponsors' demands, and International Film Festival requirements.
\end{abstract}

Keywords: Film Industry, Language Transformation, Socio-Cultural Identity, Bongo Movies

\section{Introduction}

This paper investigates factors for style shifting in contemporary films produced by Tanzanian Film industry. These are also known as Bongo movies. It starts by describing the sociolinguistic profile of multilingual Tanzania. It further explains the functional distribution of languages in various domains, comparative status, and power assigned to various languages and how they may relate to factors for a style shifting of the language used in Tanzania Film Industry.

\subsection{Sociolinguistic Profile of Tanzania}

The African continent presents one of the most complex linguistic situations in the world, owing to the number of languages, the diversity of language families and the functions assigned to various languages in the same country. In Tanzania particularly, this complexity is not only reflected in the number of languages spoken by communities of varying sizes, but also by the comparative power, status and functional domain assigned to various languages. Being a multilingual society, language use in Tanzania widens from Ethnic Community Languages (ECLs) through Swahili, the national and official language, consequently to English, the official and international language. Speaking of language use in Tanzania, Abdul-Aziz Mkilifi (1972:198) proposes that languages are assigned roles in complementary distribution. The ECLs are acquired and used in homes and in informal domains such as traditional rituals. The ECLs, which could be termed "minority languages" in terms of their status, prestige, and literacy, are spoken by most people particularly in rural settings. Kiswahili occupies the second level as the national language and one of the official languages. 
Kiswahili commands prestige as a standardized lingua franca used extensively in the education system, mass media, and government administration. It is first learnt in primary schools hence spoken by the overwhelming majority of the Tanzanian population. It is the language prescribed by law for use in most governmental matters, in addition to being the medium of instruction in all government primary schools and a subject or course in secondary and higher education institutions respectively. It thus fosters unity and has become a symbol that expresses and mobilizes national pride. It is used in official day-to-day administration to ensure the smooth functioning of the political, socio-cultural and economic systems of the nation. It also guarantees access to these systems to different social groups and equal opportunity to participate in them at the national level. English is a world language used for international communication and is highly prestigious in terms of economic and political power. The English language is for higher education, the high court and the court of appeal, diplomacy, foreign trade and other international business dealings that cut across international levels (Rubagumya 2009:109). While Kiswahili is associated with nationalism, power, modernity and dynamic life (Mekacha 1993), English is connected to new culture, entertainment, highly paying jobs, internationalism, and globalization. Moreover, in Tanzania English language is equated to literacy and success in life.

There are no open conflicts or social clashes regarding the functional distribution of the languages according to their relative power and status. However, individuals realise on a daily basis that by virtue of their social, political and economic status, English at one level and Kiswahili at another become prerequisites for access to power and upward mobility in Tanzania (Rubagumya 1989:109). There is a rapid functional shift from the non-prestigious languages to the prestigious as a result of economic and political pressure within the country and from the international level. This rapid functional shift is affecting the Media and Film Industry in Tanzania, and this is what we seek to demonstrate.

Like any other sectors, the film industry in any country contributes to the economy by creating employment opportunities, boosting tourism if published outside the country, guiding to learning diverse culture etc. However the film industry is always dynamic in terms of its technology and creativity, application of social-cultural activities and changes in global economy, political and ideological ideas of certain period of time trying to cope with the issues related to global networking. Lorenzen (2007) argues that globally, the film industry is shifting from films produced for home country audiences to products produced for global consumption i.e. products that are able to reach diverse audiences around the world. The shift is facilitated by new distribution and exhibition forms such as Satellite TV, internet, and DVD. Current film projects involve crossborder co-production where companies share expert skills, creativity, and locations. There is an emergence of diversified multimedia corporations that are owned globally operating finances, marketing and distributing films. These transformations affect not only the content of films and how media may smoothly function but also how the language as a medium of transmitting that content may be used. This may lead to the use of more than one language or subtitle in order to capture new or foreign audiences that may be unfamiliar with the original language of the films. Heiss (2004) found that since 1980s and 1990s, the number of film productions requiring the audience to deal with more than one language increased. German producers responded by including English subtitles in films like Funny Games, Knocking on Heaven's Door, and Crazy. Transformations in the film industry may also lead to the use of code-switching such as in Slumdog Millionaire that uses both English and Hindi (David and DeAlwi 2009) to reflect not only the multilingualism of India but also to expand its audience from merely the Indian subcontinent to an international audience.

Speaking of Film Industry Development and Challenges in Tanzania after 50 years of independence, Mbura (2012) argues that, Tanzania Film industry is experiencing various challenges in its major activities: production, distribution, and exhibition of films. There are major changes in terms of technology, market (free economy and privatization), changes in content (from being educational to commercial films), ownership (from the public to private ownership) distribution of films etc. All these being the outcomes of Tanzania economic reforms towards free market economy through Structural Adjustment Program introduced in the 1980s with the intention to correct the economic imbalances and improve the efficiency of Tanzania economy towards development. Mwakalinga (2010) also talks about the existence of ideological shift from Socialism to open market economy and the emergence of the cultural institution which have contributed to the commercialization of the film industry. These changes go hand in hand with making use of English language instead of Kiswahili which was previously used in films such as Mhogo Mchungu, Chalo Amerudi, Juma Matatani and Wageni Wema of the 1950s when the film industry was involved in making educational films used as the important tool for propagating ideology. Also, films such as Fimbo ya Mnyonge, Kupe ni Adui wa Haki were used to advocate the ideology of Ujamaa (Socialism) and Self Reliance in the 1970s. Also in the 1980s more educational films were produced namely as Arusi ya Mariam, Yomba Yomba, Mama Tumaini, Fimbo ya Baba to mention but few.

Currently, most film titles are written in English for commercial purpose, scripts are given with English subtitles to comply with the international market and DSTV broadcasts, but film characters highly borrow words from English to Kiswahili, code-switching from Kiswahili to English. This is observed in movies such Young Billionaires produced by GRM production Crazy Love produced by Game 1st Quality, Happy Couples produced by Pilipili Entertainment Co. Ltd, Fake Pastors, etc. Code-switching in the bilingual community often reflects the social or cultural identities of the speakers (Myers Scotton 1993). Code- 
switching helps to achieve the interactional goals with other speakers or audience. It is used to signal authority found in the prestigious language (the language switched to, in this context English), ethnic or group identity. Thus this paper has sought to uncover the magnitude of language shifting from less to highly prestigious languages in media and film industry in multilingual Tanzania, Kiswahili and English being the cases. It has unveiled the motivation behind style shifting particularly code-switching/mixing and the sudden changes that accommodate the English language in Tanzania Film Industry particularly in films' titles and subtitles using the following questions. Is using English titles and subtitles in the Tanzania's Kiswahili films and code-switching from Kiswahili to English a result of:

i. A transformation in functional distribution of languages in multilingual Tanzania from Kiswahili which was previously used in media and arts to English, the more prestigious language that commands socio-economic power and authority?

ii. A cultural transformation and the way of constructing a new identity related to the use of the language of authority i.e. English?

iii. The way to comply with free economy and privatization of media along with new techniques of production and distribution where English is inevitable? Or

iv. A strategy for success i.e. attracting and capturing new audience especially youth and for the global market?

\subsection{Theoretical Framework}

The study is guided by the Speech Accommodation Theory (SAT), a socio-psychological model of speech style modifications developed by Howard Giles in 1973 clarifying the motivations underlying speech accommodation strategies namely convergence and divergence. It needs to understand the motivation for style-shifting and code-choice in a different context of a conversation. SAT claims that during conversation speakers adjust their speech patterns to decrease or increase their communicative distance between themselves and their interlocutors. This adjustment may involve shifting from less standard speech forms to the highly standardised and prestigious speech forms or language. Speaking of convergence, Giles and Coupland (1991) argue that this is a linguistics strategy in which speakers adapt each other's communicative behaviours in terms of a wide range of linguistics-prosodic-non verbal features including speech rate, pausal phenomena and utterance length, phonological variants, smiling, gaze etc. On the other hand, divergence is a strategy geared at accentuating the vocal difference between speakers and their interlocutors. The motivation for divergence is to retain speaker's group identity by making the distinction from other groups. SAT aims at adjusting speech patterns to promote interlocutors comprehension and increase mutual intelligibility (Bell 1984; Coupland 1984) hence increases communicative efficiency, to gain interlocutor's approval, and to maintain the positive social identity (Beebe and Giles 1984). Giles et al. (1991) argued that SAT plays role in the situation of language switching when bilinguals must decide which language they should speak when they are in the environment with other bilingual individuals. One of the strategies of SAT is that people will attempt to maintain their speech patterns or even diverge linguistically away from those believed characteristic of their recipients when they (a) define the encounter in intergroup terms and desire a positive in-group identity (b) wish to dissociate personally from in an inter-individual encounter, or (c) wish to bring another's speech behaviours to a personally acceptable level (Bourhis and Giles 1977: Taylor and Royer 1980; Cappella 1991). Language and behaviours impart information about social status and group belonging. The SAT model deems fitting to this study which seeks to demonstrate the motivations for style shifting specifically code-switching from Kiswahili to English, use of English titles and subtitles in Tanzania films (Bongo movies).

\section{Methodology}

Data for this paper were collected from Dar es Salaam region mainly because it would be easier to get relevant information from respondents of all categories such as movie characters, directors, producers and distributors who mainly live in the county. Moreover, most film production companies are situated in Dar es Salaam. Data collection employed two main techniques; review of audio-visual tools (DVD for Movies) and telephone interviews. In reviewing of audiovisual tools, a sample of 11 Tanzanian films (Bongo movies) which were produced after the year 2000 were collected so as to examine the status of language transformation. These movies include Tunu, Crazy Love, Young Billionaires, Happy Couples, Red Valentine, Dangerous Desire, Deception, Unfortunate Love, Hero of the Church, Laptop and Fake Pastors. The audio-visual review involved watching movies several times so as to be familiar with the interactions between movies characters. Scenes which exemplified incidences of code-switching were selected, transcribed, categorised into their structural levels and analysed. Through telephone interviews, 2 film directors and producers, 2 film distributers, 6 actors and actresses were interviewed. These film stakeholders were purposely selected based on their familiarity with Tanzanian film industry.

\section{Results and Discussion}

This section presents the results and discussion of the findings obtained in this study. It describes first the status of the language used in Tanzanian films before and after 1961, then it presents and discusses the factors for style shifting of the language used in Bongo movies.

\subsection{The Status of Language Used in Tanzanian Film Industry Before and After 1961}

According to (Mbura 2012) and Philemon (2013), among the movies which were produced before 1961 include Muhogo Muchungu, Chalo Amerudi, Juma Matatani and 
Wageni Wema. These movies were produced in 1950s, and only Kiswahili was used, and they revealed the identity of Tanzanian Film Industry through Kiswahili. These movies neither had English titles, English sub-titles nor codeswitching.

Philemon (2013) reveals that after 1961, there were two periods of film industry development in Tanzania in which there is the different status of the language used in movies. The first period was in 1980s in which movies were sponsored by outsiders. In this period of time, the status of the language used in Tanzanian movies started to change because sponsors demanded the movies to be subtitled in English so as to be understood to the mother country of the sponsors. These include Arusi ya Mariam, Yomba Yomba, Mama Tumaini to mention a few, produced by Tanzania Film Company (TFC). These were subtitled in English but had neither English titles nor code-switching.

The second period is from 1990s up to date. In this period, most of the movies have English sub-tittles; English titles and movies' characters tend to code-switch. Some movies bear Kiswahili titles but have English subtitles like Fimbo ya Mnyonge, Tunu, Maangamizi, Fimbo ya Baba, Chukua Pipi, Kokoni Kulikoni. Movies such as Crazy Love, Young Billionaires, Happy Couples, Red Valentine, Dangerous Desire, Deception, Unfortunate Love, Hero of the Church, Laptop Fake Pastors, which were produced in the 2000s proved to bear English titles, English subtitles and codeswitchings.

From the data which were collected from the reviewed sampled Tanzanian movies, there were a total of 188 tokens in the data set of code-switching and lexical borrowings. The code-switching tokens were categorised in terms of tag switches, inter- sentential and intra-sentential switches (Romaine 1995; Sebonde 2012) with a consideration of the Matrix Language Frame Model of Myers-Scotton (1993; 2006).

Tag switching involves the insertion of a tag from one language into an utterance in another language. The term 'tag' covers elements like discourse markers, and affirmative and negative particles. Romaine (1995:122) comments that, since tags are subject to minimal syntactic restrictions, they may be inserted in a number of points in a monolingual utterance without violating syntactic rules. In this study, about 56 tokens were of tag switches. The following examples illustrate the occurrence of tag switches in sentence constructions.

Example 1:

(a) Aaah! Mimi mjinga sana, kichwa changu kinasahau sana nilikuwa nimeandaa DVD hiyo tayari kabisa sijui nimesahauje? Anyway! I promise kesho nitakuletea hiyo DVD. (Aaah! I am very stupid, I tend forget. I had already prepared a DVD but I don't know how have I forgotten it? Anyway! I promise to bring you that DVD tomorrow) (Source: Laptop movie)

(b) Speaker A: Ohh! mume wangu! How are you?

(c) Speaker B: (silence)

(d) Speaker A: Nicolas, are you ok my honey? (e) Speaker B: Yeah! I am ok. (Source: Red Valentine movie)

(f) Speaker A: Mimi ni star

(g) Speaker B: Aaah! Wewe ni star (Aaah! You are a star)

(h) Speaker A: Eeeh! (Source: Young Billionaires movie)

(i) Ohh! My friend unafanya vizuri kufanya mazoezi (Ohh! My friend is good to exercise) (Source: Crazy Love movie)

Inter-sentential switches category involves a language alternation between sentences. It involves producing one or more sentences in one language before producing a sentence from the other language (s) in use within a speech event (Myers-Scotton 1993:3-4). They may occur within and across speakers' turns, and they are thought to require greater fluency in both languages. This is because major portions of the utterance must conform to the rules of both languages. In this study about 153 tokens were of inter-sentential switches and examples in 2 below illustrate these constructions as they occur in the sentence structure. Illustrations for codeswitching are in bold form.

Example 2:

(a) Wewe! That is out of my mind. Hivi wewe huko ulikotoka hukufunzwa namna ya kuishi na mwanamume? (You... Were you not taught how to live with a husband?) (Source: Dangerous Desire movie)

(b) Speaker A: Buyu ametoka. I hope Fani will be okay too. (Buyu is out)

(c) Speaker B: Things gona be okay. So you are going to sing tonight, sio? (Isn't it?)

(d) Speaker A: Now without Buyu being there.

(e) Speaker B: Na imani atakuja. (I hope he will come) (Source: Happy Couples movie)

(f) Mama usiwe na wasiwasi, I am a big boy, I can handle myself, trust me. (Mother, don't worry...) (Source: Crazy Love movie)

Intra-sentential switching involves switching forms 'within the clause or sentence boundary' (Romaine 1995:123) and sometime includes mixing within word boundaries, where there is an insertion of inflectional morphology from another language. In this study, about 166 tokens were intrasentential switches, of which 79 tokens were at word level category, 71 tokens were at phrasal and clausal level categories while 16 tokens involved mixing within word boundaries. Examples 3(a)-(e) give evidence for the construction that involve phrasal and clausal categories of code-switching. Examples 3(f)-(h) demonstrate constructions of code-switching that involve inserting morphological inflection within word boundaries. The word structure is of a matrix language Kiswahili while the word roots are of the embedded language, English.

Example 3:

(a) Nina appointment na Happy nikamfanyie shopping (I have an appointment withHappy I want to shop for her). Source: Young Billionaire movie)

(b) Nenda msikitini, kanisani, you will find a nice girl anayekufaa. (Go to the mosque, church, you will find a nice girl that suits you). (Source: Young Billionaire 
movie)

(c) Kwa bahati nimekutana na doctor naye amenipatia discharge. (Fortunately, I have met a doctor and has discharged me). (Source: Tunu movie)

(d) Nelson hujui hata ni birthday yako. (Nelson, you don't know that it is your birthday). (Source: Crazy Love movie)

(e) Hii ni business card yangu kama likitokea jambo lolote la dharura utanipata. (This is my business card that you may use to get me through in case of any emergency). (Source: Tunu movie)

(f) Aaah! Nilikuwa nadeki na kufua nguo. Nikaona ni-mesweat nikaona nioge. (Aaah! I was mopping and washing clothes. I decided to take a shower after sweating). (Source: Deception movie)

(g) Kwa hiyo u-na-ni-promise? (So are you promising me?) (Source: Young Billionaire movie)

(h) Nafurahi kuwa u-na-enjoy kazi yako (I am happy that you are enjoying your work) (Source: Happy Couple).

Examples 3 (f)-(h) include verbs that can well be classified as in morphological aspects below;

Ni-me-sweat

SP $1^{\text {st }}$ PS- T/A-sweat

'I have been sweating'

U-na-ni-promise?

SP2 ${ }^{\text {nd }}$ PS- T/APRES- OP1stPS - promise

'Are you promising me?'

U-na-enjoy

SP2 ${ }^{\text {nd }}$ PS-T/APRES-enjoy

'You are enjoying'

\subsection{Factors Underlying the Style Shifting of Language Used in Tanzanian Movies}

From the data which were collected for this study, several factors underlying the motivation for style shifting of the language used in Tanzania movies were obtained. These were thematically categorised to factors such as socio-cultural identity construction, a reflection of multilingual country, free market economy, sponsors' demands, film festival requirements, co-production, and contextual factor.

\subsubsection{Socio-Cultural Identity Construction}

A person's identity is constructed through social relations. Language is inevitably contributing to defining a person's identity through interaction. Through language, we can explain to others, who we are, or a group of people or a community we belong. Speaking of language and identity, Wardhaugh (2006:114) states that "we are what we are, but we do have the ability to present ourselves in different ways". Our verbal behaviour can be one of the tools to express what we think, but also the choice of words, voice, intonation, and how they are employed, are essential components in presenting our identity. Thus when one changes a language, the identity will also change to diverge or converge oneself from or into a group or community hence code-switching can be used as a way of showing bond or distancing oneself from speakers of a language or code.
Identity construction in this study is reflected through two major components which are firstly, identifying themselves with educated people and secondly, through imitation from outside country movies characters.

Concerning education and identity, data in this study revealed that the use of code-switching and English subtitles in Tanzanian movies reflects what is taking place in the society. In Tanzania, the English language is associated with better education and high-quality life, given the economic opportunities that come with the ability to use the English language. Many people like to associate themselves with educated people through attempting to demonstrate that they have grown up in the environment where the English language is commonly used. Like other people in the society, movie characters code-switch to English in order to show off or make an impression to the audience that they have gone to school hence trying to identify themselves with the educated people through the use of English. This was because in the previous years movie acting or engaging in the film industry in Tanzania was considered as a sign of lack of opportunity to earn living and actors and actresses were regarded as non educated people. This implies that movies actors and actresses diverge from less educated or people with no economic opportunity and converge to the educated ones through the use of English language. Nevertheless, the study has shown that together with other factors, code switching and code mixing in Tanzania also result from an inadequate acquisition or lack of proper vocabulary that can communicate the intended meaning or concept.

Speaking of the issue concerning imitating outsiders, the data revealed that Bongo movie film stakeholders are copying some features from Bollywood and Nollywood in film making. Studies show that the consumption of Nigerian films was at its peak in Tanzania between 2003 and 2006, a viable local video industry developed in Dar es Salaam labelled as Bongowood (Philemon 2013). Like its big sister, Nollywood, the Dar es Salaam-based industry has its root in local drama and television production. Most productions are realized by independent drama groups and marketed national wide and beyond by the only handful of producers and distributors. Although Bongowood has a long way already, Nollywood still serves as a kind of reference points for a number of filmmakers, their critics, and spectators. The study realised that the use of English titles is the product of imitation from Nigerian movies by Tanzania actors and actress aiming at capturing the local and external audience. Thus, incorporating subtitled movies is a means of convergence to English speaking making other people who have no command of Kiswahili language to understand the movies, at the same identifying with Nigerian film making.

\subsubsection{A Manifestation of Multilingual Country}

It was revealed that language adjustment in Tanzanian movies is a genuine manifestation of sociolinguistic experience by the people in the multilingual society. The use of code-switching is significantly reflecting Tanzania social reality as it is commonly used while conversing. It was 
explained before that, Tanzania is a multilingual country and studies have shown that there is a significant change and functional shift of language use in different domains or social situation. This leads to labelling some languages like English as more powerful in terms of status and prestige than others. In Tanzania code-switching is common in advertisement in the mass media, in schools (Kanyuma 2005), buses, and telephone conversation (Ramadhani 2013), at the market, hospitals (Sebonde 2012) parliamentary assembly hall (Bwenge 2009), in emails and in different social networking such as Facebook, Twitters and blogs (Msamaa 2015). This implies that this language transformation particularly codeswitching reveals what some people are accustomed to in their real life. The films portray social reality in the society. The script writers have managed to portray the real life and daily practices in the multilingual Tanzanian society.

\subsubsection{Free Market Economy}

The study revealed that Tanzania movies industry is growing so fast hand in hand with the free market economy. Currently, the business of films is becoming universal for everyone and not for an individual group or country. Like other movie industries such as Bollywood in India and Nollywood in Nigeria, Tanzania movie industry has crossed the national borders in terms of the market. It was established from the data of this study that English subtitles are employed in Tanzania Swahili movies to capture the market for the local and international audience. The movie industry stakeholders such as characters, directors, producers, and distributers use English subtitles as a strategy to converge to the language of the international market. The use of English subtitles and English titles helps distributors to sell to nonKiswahili speakers especially foreigners. It was revealed that subtitling is special for the people who do not know the original language of the movies, so must be subtitled in common language which is well understood by the majority outside the borders of Tanzania like the English language. For example movies like Dangerous Love, Red Valentine reveal the use of English subtitles to make others who do not have a good command of Kiswahili inside and outside Tanzania to understand the movies. With the aid of English subtitles nowadays movies from Tanzania cross the borders more easily.

\subsubsection{Sponsors' Demands}

The study exposed that sponsor's factor is another aspect which is worthy to be brought up in the use of English subtitles. It was revealed that one of the reasons for the use of English subtitles is the requirement from the sponsors and distributers who decide to sponsor the actors and actresses. The producers who happen to be sponsors insist on the use of subtitles in their movies in order to find the new audience beyond Tanzania. In 1980s for example, the films of Arusi ya Mariam and Mama Tumaini produced by Tanzania Film Company were sponsored by the foreigners who demanded the movies to be subtitled in English so as to be understood by viewers abroad including sponsors' countries. While these sponsors produced resources like fund and equipments,
Tanzanians produced human resources and locations where the movies were to be shot. For that matter the sponsors who were foreigners conditioned those movies to be subtitled in the English language.

On top of that, subtitling is also demanded by the world satellite like DSTV broadcast in South Africa and ZUKU from Kenya which need movies to be subtitled in English for the foreigners to view and understand.

\subsubsection{Film Festival Requirements}

The findings in this research also revealed that Film Festival has led to language change in Tanzania film industry. The annual International Film Festival grants the best film Award hence it requires movies to be presented with English subtitles for the movies to be judged easily. This has encouraged some Tanzania movies stakeholders to empower themselves in using the English language for their movies to pass through fair judgement and win the competition in the International Film arena. The International Film Festival also encourages film with English subtitles with the aim of capturing the audience.

\subsubsection{Co-Production}

It has been observed that most of the movies which were produced both in Tanzania and outside the country have English titles, scripts have subtitles and movie characters use English and code switch. For example in 2006, Mtitu Game 1st, a movies producing company from Tanzania produced a movie Dar 2 Lagos with Nigerian company. This movie was shot using Nigeria and Tanzanian locations involving movies characters from both countries. Mtitu Game 1st was able to convey the sensation of Nollywood directly to his film. This is the first Tanzanian film shot in Nigeria with real Nollywood movie characters and Nigerian director (Femi Ogedegbe) (Philemon 2013). In this movie, there is a lot of code-switching/mixing and there is the use of English subtitles and English title Dar 2 Lagos. In addition to that, the movie characters from Nigeria mostly used English while Tanzanians used Kiswahili which they are conversant with. In this kind of movie code-switching/mixing, English subtitles and English titles were inevitable. In this way, Tanzanian movie producers diverge from the in-country production and the use of Kiswahili to co-production with foreign companies hence the use of English language.

\subsubsection{Contextual Factor}

The study realized that code-mixing and switching depending on the type of context in which the movies are acted. For example, in the movie of Laptop, there is switching between Rita and Mwalimu in the classroom context when Mwalimu is asking Rita to tell the reasons why Rita is not writing, here the context allows to code-switch in the movie as a way of presenting the school environment. Moreover, in the University context, for example, code mixing and code switching is very common because of the environment of the learned persons. If the movie story itself shows the person who does not know the language of the hosts, code-switching is commonly used for the intention of 
meeting the mutual intelligibility in the movie. In addition, the study found that code-switching and mixing can be seen to occur when the characters communicate with the addressee of different domains such as family domain, friend domain as it is supported by Skiba (1997) who states that there are patterns where code-switching occurs with regard to the addressee and the locations in order to ensure that an appropriate language is used for a particular group.

\section{Conclusion}

This study has presented a motivation for style shifting from Kiswahili to English specifically on the use of codeswitching, English title, and sub-titles in the Bongo movies. Based on the information collected through reviewing of movies, it was revealed that movies produced in 2000s have fully utilization of code-switching which were structurally presented in form of tag, intra-sentential, and inter-sentential switching. The reviewed movies had English titles and subtitles. The information which was collected through interviews revealed that Bongo movies stakeholders are using English titles, subtitles and code-switching as a way of constructing socio-cultural identity. This is revealed through diverging from the use of Kiswahili which is considered as a language of less economic opportunities and less educated; and converging to educated people who mainly use English, the prestigious language that commands socio-economic power and authority, and through imitation from outside movie makers like Nigerians. Style shifting and adjusting codes in speech patterns is a strategy to attract, accommodate and increase the new audience from the international market after globalisation and internationalising media. More over it is a strategy to comply with free economy and privatization of media along with new techniques of production and distribution where English is a necessity. Different from the movies produced in the $1980 \mathrm{~s}$, movies produced in 2000 s are made to capture the audience for commercial purposes within and outside Tanzania boundaries and they reflect changes in technology and creativity as well as global networking. On top of all the factors, adjusting speech patterns is a reflection of sociolinguistics profile of a multilingual Tanzania because, beside media domain, they also code-switch in other language domains such as school, markets, hospitals, parliaments etc. So while adjusting the code in one hand is about constructing identity with outsiders and highly educated people; and attracting the international market for films, on the other hand, it is a sign of language transformation and a reflection of the sociolinguistics profile of the multilingual Tanzania where English, Kiswahili, and Ethnic community languages co-exist.

\section{References}

[1] Abdulaziz-Mkilifi, Mohamed, H. (1972). Triglossia and Swahili-English Bilingualism. Language in Society. 1:197213.
[2] Beebe, L. M. (1974). Socially Conditioned Variation in Bangkok Thai. Unpublished Ph.D. Thesis, University of Michigan.

[3] Beebe, L M., and Giles, H. (1984). Speech-accommodation theories: A Discussion in terms of second- language acquisition. Int'l Journal Soc. Lang. 46:5-32.

[4] Bourhis, R. Y. and Giles, H. (1977). The language of intergroup distinctiveness. In Language, Ethnicity and Intergroup Relations. H, Giles (ed) 119-135: London, Academic Press.

[5] Bwenge Charles. (2009). Linguistic Identity (re) Construction in Electoral Politics: The Case of 2005 Tanzanian Parliamentary Campaigns. Selected proceedings of the 39th Annual Conference on African Linguistics.

[6] Cappella, J. N. (1981). Mutual Influence in Expressive behaviour: Adult-adult and infant-adult dyadic interaction. Psychological Bulletin. 89:101-132.

[7] Mbura, Issa. (2011). Tanzania Film Industry Development and Challenges in Tanzania after 50 Years of Independence. Dar es Salaam: DUP.

[8] Mekacha, Rugatiri, D. K. (1993). The Sociolinguistic Impact of Kiswahili on Ethnic Community Language in Tanzania: A case study of Ekinata. Bayreuth: African Studies.

[9] Mwakalinga Mona Ngusekela. (2010). The Political Economy of the Film Industry in Tanzania: From Socialism to an Open Market Economy 1961-2010. Ph.D. Thesis: University of Kansas.

[10] Myers-Scotton, Carol. (1993). Social Motivations for Codeswitching: Evidence from Africa. Oxford: Clarendon.

[11] Myers-Scotton, Carol. (2006). Multiple Voices: An Introduction to Bilingualism. Malden: Blackwell.

[12] Philemon Edwin. (2013). Language Change in Tanzania Film Industry. MA Dissertation: The University of Dodoma.

[13] Ramadhani, Z. (2013). The Impact of Text Messaging on the Acquisition of Standard English Writing in Tanzania: A Study of Higher Learning Institutions in Dodoma Municipality. M. A. Dissertation: The University of Dodoma.

[14] Romaine, Suzanne. (1995). Bilingualism. (2nd ed.). Oxford: Basil Blackwell.

[15] Rubagumya, Casmir, M. (1989). English Medium Instruction in Tanzania Secondary Schools: A Conflict of Aspiration and Achievements. Journal of Multilingual and Multicultural Development, 11:107-115.

[16] Rubagumya, Casmir, M. (ed). (1990). Language in Education in Africa: A Tanzanian Perspective. Cleveland: Multilingual Matters.

[17] Sebonde R. Y. (2012). Code-switching and Social Stratification in a Rural Chasu Community in Tanzania. Language Matters. 43 (1) 80-96.

[18] Skiba, R. (1997). "Code-switching as a Countenance of Language Interference". The Internet TESL Journal, Vol. 3, No. 10, 1-6.

[19] Yesse, Kanyuma. (2005). Social Motivations for CodeSwitching among Members of Primary School Communities: A case study of Rabuor Ward, Tarime District. M. A. Dissertation: University of Dar es Salaam. 